\title{
PHASING SCHEMES FOR THE CEBAF CAVITIES*
}

\author{
S. N. Simrock, R. Kazimi, G. A. Knfl, L. Merminga, L. Ninan, S. Witherspoou \\ Continuous Electron Beam Accelerator Facllity \\ 12000 Jefferson Avenue, Newport News, VA 23606-1909 USA
}

\begin{abstract}
The CEBAF accelentior requires sccurate phasing of the 338 superconducting cavities to actieve the destign mins energy spread of 2.5-10 $10^{5}$. The rms phase error along each linac, with 160 cavities over a length of $200 \mathrm{~m}$, may not exceod $2.6^{\circ}$, essuming that the whole linac is operated oe crest. The common procedure is to maximize the energy gain with a spectrometer. At CEBNF, bowever, phase-dependent cavity iteering effects cause deflections of the beam of sevenal mind. requiring steering corrections in the linac, which makes this method very time coesuming. Beam-induced transients can also be used in pulsed operation to determine the zero-energygain phase with bigh sceuracy. Better than $2^{\circ}$ sceuncy is achieved when the algnal-to-Doise ratio is inproved by signal averaging. These and other approacbes for the phasing of cavities are comparod and accuracy and feacibility are discussed.
\end{abstract}

\section{PHASE STABILITY REQUIREMENTS}

The overall specification for the CEBAF accelerator is given in Table 1.

Table 1: Accelerntor Permeters

\begin{tabular}{|l|l|l|}
\hline Energy & $\mathrm{E}=0.5-4.0$ & $\mathrm{GeV}$ \\
\hline Energy spead & $\sigma_{\mathrm{P}} / \mathrm{E} \leq 2.5 \cdot 10^{-5}$ & at $1 \mathrm{GeV}$ \\
\hline Beam arment & $0=200$ & $\mu \mathrm{A}$ \\
\hline
\end{tabular}

The low exergy spread of the beam requires strict amplitude and phase control of the RF field in the supercoeducting cavities according to table 2 .

Table 2: RF amplitode and phase stability requirements with vemier system maintaining linac on crest

\begin{tabular}{|c|c|c|}
\hline & increnclaned & conclated \\
\hline$\sigma_{A} / \mathrm{A}:$ endieat arror & $2 \cdot 10^{-4}$ & $1.1 .10^{5}$ \\
\hline 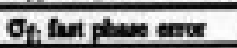 & $0.25^{\circ}$ & $0.13^{\circ}$ \\
\hline$\sigma_{1}$ alow phase aror & $2.6^{\circ}$ & - \\
\hline
\end{tabular}

The rms phase error along a linac with 160 cavities may not exceed $2.6^{\circ}$. A phase vernier system will maintaln the overall phase of the linacs on crest while a gndient vernier [1] system will maintain constant energy at the end of the linac. With the overnill phase of the linac being on ereat, the tndividual cavitles need to be phased better than $\$ 52^{\circ}$ to meet the specification in table 2. The goel is to initially plase cavities better than $\pm 2^{\circ}$.

\footnotetext{
- Supparted by U.S. DOE coetract DE-AC05-84ER40150
}

\section{PHASING SCHEMES}

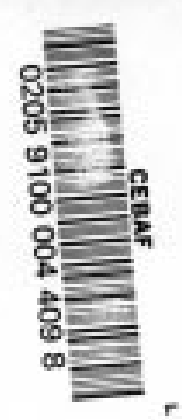

During socelerator operntion the phase of the sccelersting field of individual cavities mast be maintained better than $\$ 5.2^{\circ}$. When the RF system is turned on for the first time, the sctual sccelenting phase is not known, since the electrical length of the probe cables may differ by more than $\pm 180^{\circ}$. The electrical length can be measured with a TDR or network analyzer and be used to calculate the actual phase as described in Section VII. This method is not very sccurate, since RF coetrol module internal phase ahifts and the geometry of the cavities to ealeulate the driftime of the beam have to be taken into account. More sccurate are measurements which use the beam as refereace. The following phasing methods have been evaluated during north linac operation at typical energies between $100 \mathrm{MeV}$ and $150 \mathrm{MeV}$ with more than 100 supercoeducting cavities opentional:

- Pasing of cavities by maximizing energy with a spectrometer as energy detector.

- Phasing of cavities by minimizing beam-induced transients during pulsed beam operation to determine the phase with zero energy gain.

- Phasing of cavities by measurement of the phase of the beam-induced field with a phase detector in the RF control modale.

- Phasing by minimizing residual gradient fluctuatices due to beam curreat modulation to determine the phase with zero energy gain.

In some cases the phase for maximum energy gain (crest phase) is determined diroctly; in other cases the phase for zero eaergy galn (zero crossing of the sccelerating field) is determined and a $90^{\circ}$ offuet added or subtracted to set the crest phase.

\section{PHASING WTTH SPECTROMETER}

Cavity phasing with the spectroeneter makes use of the dependency between energy gain of the cavity and phase of the accelerating field. The energy gain is maximized using a spectrometer. This method can be automated and computer controlled.

\section{Manual Phasiag}

For the initial cavity phasing a spectrometer at the end of the borth linac whs used. Changes in energy were observed ce a view screen with a radius of $17.5 \mathrm{~mm}$ corresponding to an energy change of $-1 \%$ at an energy of $100 \mathrm{MeV}$. In the spreader region at a location with a dispersioe of $1.1 \mathrm{~m}$, a position revolution of $0.1 \mathrm{~mm}$ corresponding to an energy 
change of $1 \cdot 10^{-4}$ can be detected. At a field gradient of 5 $\mathrm{MV} / \mathrm{m}$ the actieved phase resolution is

$\phi=\cos ^{-1}\left(1-\frac{\Delta E}{E_{0}} \cdot \frac{E_{0}}{E_{\text {acc }} / 2}\right)=2.56^{\circ}$

for a rpectrometer resolution of $(\Delta E / E)=1 \cdot 10^{-4}$

with $E_{0}=100 \mathrm{MeV}$ and $E_{\text {aec }}=5 \mathrm{MeV} / \mathrm{m}$.

Cavity steering effects are significant and require correction of the beam opeics especially if cavities at the begineing of the linac are phased. Manual phasing with the epectrameter has been provea to be very time consuming but is required colly ooce for initial phasing of the accelerntor. Periodic phase corrections are performed using avtomated algorithms. It is expected that the resolation will increase significantly when a Beam Position Moeitor (BPM) th the are at a beation with a bigher dispersion of $10 \mathrm{~m}$ is used.

\section{Automated Phating}

The above described method has been autcmated. The view screen for the beam position measurement is replaced by reading from a beam position monitor with a position resolution of $0.2 \mathrm{~mm}$. It is also possible to use a harp reading. The BPM is located in the spreader section at a location with a dispersion of $1.1 \mathrm{~m}$ resulting in enengy resolution of 1.10-4. The algorithm changes the phase in an individaal cavity by $\Delta \phi= \pm 30^{\circ}$, measures the initial beam position and the beam positions following the changes in phase, and calculates the creat phase from the three measured positions eccorting to

$$
\begin{aligned}
& \phi_{\text {anet }}=\tan ^{-1}\left[\frac{x_{1}-x_{2}}{x_{1}+x_{2}-2 x_{3}} \cdot \sin \left(\frac{\Delta \phi}{2}\right)\right]+\phi_{0} \\
& \phi_{0} \text { : initial phase setting } \\
& x_{3}: \text { beam position for } \phi=\phi_{0} \\
& x_{2}: \text { beam position for } \phi=\phi_{0}-\Delta \phi \\
& x_{3}: \text { beam position for } \phi=\phi_{0}+\Delta \phi \\
& \Delta \phi: \text { change in phase setting }
\end{aligned}
$$

For a final energy of $100 \mathrm{MeV}$ and a crivity eradient of 5 $\mathrm{MV} / \mathrm{m}$, a phase change of $30^{\circ}$ results in a position change of $7.4 \mathrm{~mm}$ asuming a dispersion of $1.1 \mathrm{~m}$.

The aceuracy of this method is $= \pm 2.5^{\circ}$ and takes 20 seconds per cavity. Mont of the time is required for the svernging of the BPM signal to schieve a resolution of 0.1 mm. This takes sbout 4 seconds. The satomated phasing is cely successfal if the phase is set within $\pm 90^{\circ}$. Therefore initial manual phasing is reguired. The experimental verifleation of this algorithm ahowed that the linac energy whs increased by $1.8 \mathrm{MeV}$ at en initial energy of $119.6 \mathrm{MeV}$. Reproducibility has beed verified by changing the taitial phase by $5^{\circ}$ and $10^{\circ}$, and the automated algorithm determined the sume crest phase within $22.5^{\circ}$.

\section{PHASING WTTH BEAM-INDUCED TRANSIENTS}

This method requires polsed beam. Typical beam conditions are $\mathrm{I}_{0}=200 \mu \mathrm{A}, \mathrm{r}_{\mathrm{b}}=20 \mathrm{\mu s}$ (pulse leagth), and $\mathrm{f}_{\mathrm{q}}=60$ Hx. The avenge beam current is less than $1 \mu$ and therefore does not require machine protection by the beam loss system. The expected transients for the gradient signal have been diecussed in [2]. Unity gain of the control loop is typically $-10 \mathrm{kHz}$ and therefore the effect of the gradient control bop is mall duriag woch a short polse. The control system regulates the average of the gnatient.

The observed transient amplibades for the above described beam conditicns are $170 \mathrm{mV}$ for $=0^{\circ}$ (ce crest) and $\pm 1.5 \mathrm{mV}$ for phase settings $\pm 5^{\circ}$ from the zero crosting at $\pm 90^{\circ}$. The result of a measurement is shown in Figure 1 . The observed mplitudes are consistent with the calculations except close to zero crossing. The trasilents at zero crosting are a result of the beam loading in the buncher, which causes the phase of the electron benm to change by $=2^{\circ}$ during the macropulse of 20 115. This is due to the fact that the buncher cavity is not operated at zero crosting and that the RF control system is not designed to correct for fast transients. The aignals in Figure 1 are averaged over 64 samples to improve the signal-to-soise natio. This method allows cavity phasing betier than $\pm 2^{\circ}$ if oely the first $2 \mu$ s of the transicats are observed to determine a change in sign for the transients.

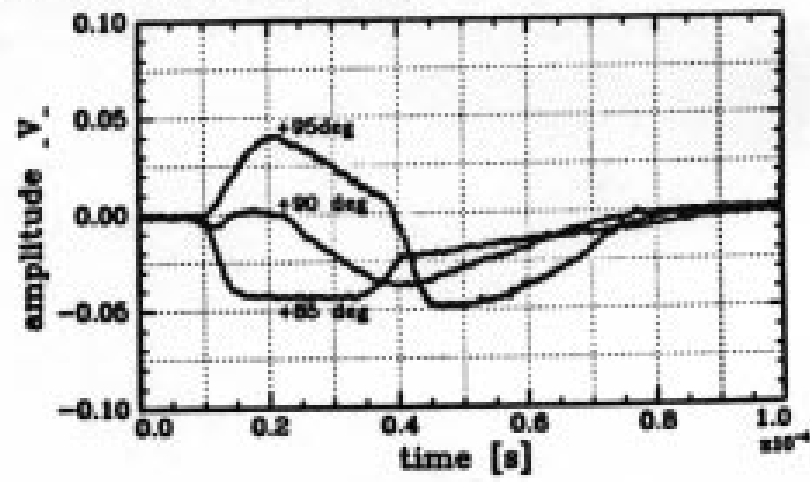

Figure 1. Measured beim-indoced transients. Phase at zero crossing and $\pm 5^{\circ} . \mathrm{I}_{0}=250 \mu \mathrm{A}, \tau_{0}=20 \mathrm{~s}, \mathrm{~L}_{\mathrm{q}}=60 \mathrm{~Hz}$. Signal amplified by $30 \mathrm{~dB}$.

It is possible w implemeat the transieat phasing method in the embedded microprocessor code for the RF control module using the modale taternal digitizer. The gradient error aigal is amplified by $50 \mathrm{~dB}$ and will be afficiently large coenpered to $25 \mathrm{mV}$ ADC resolution to determine the phase better than $\pm 5^{\circ}$.

\section{v. PHASING WITH BEAM MODULATION}

This method is similer to the phasing with transients since it weses beam-laduced gralient fuctuations to determine the phase at zero crossing. The beam curreat is modulated as 
$I=I_{0}+\Delta V \cdot \sin \left(\omega_{m} t\right)$

$\Delta J$ : amplinde of carrent modulation (Vp. $1 \mu \mathrm{A}$ )

$\omega_{\ldots}$ : frequency of current modulation (typ. $100 \mathrm{~Hz}$ )

The beam-laduced gradient will be $6.4 \mathrm{kV} / \mathrm{m}$ resulting in - detector error of $6.4 \mathrm{mV}(5 \mathrm{Vm} \mathrm{MV} / \mathrm{m})$ if the gradient loop is open. This transhates into $-6 \mathrm{mV}$ gratiest modalator dive (at $100 \mathrm{~Hz}$ ) if the gradient bop is closed. The apectrum of the endieat modulator drive is shown in Figure 2 . The dominant microphoeic solie component at $56 \mathrm{~Hz}$ has twice the amplitude, and the broedbend noise within a bendwidth of 50 kHis as acquired by RF control module internal ADC is 20 $\mathrm{mV}_{\mathrm{p}}$. Te signal is too amall to be analyzed within the RF coefirol module, but if processed in the mactine control rocen using the analog monitor system [3], it is possible to phase cavities better than $\pm 5^{\circ}$.

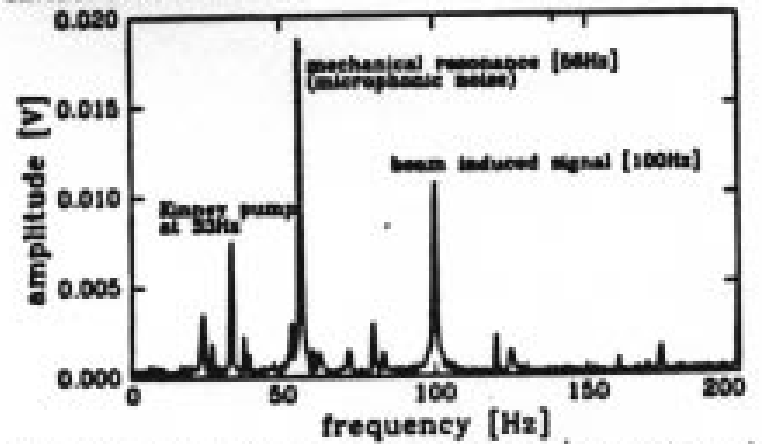

Figure 2. Spectrum of gradient moduiator drive with modulated beam. $\Delta /=1 \mu \mathrm{A}$ and $f_{m}=100 \mathrm{~Hz}$

\section{PHASING WITH BEAM-INDUCED GRADIENT}

This method requires $\mathrm{CW}$ beam. At least $10 \mathrm{HA}$ of beam current is required to excite a sufficiently large field gradient to measure a phase error relative to the phase referesce derived from the master oscillator. The cavity is not powered by the klystroe. The phase setpoint is adjusted to nall the phase error signal. Typical sensitivity is $100 \mathrm{mV} / \mathrm{deg}$ ree at $5 \mathrm{MV} / \mathrm{m}$ or $1.27 \mathrm{mV} / \mathrm{deg} r \mathrm{e}$ for $10 \mu \mathrm{A}$ of beam curreat which excites a field of $63 \mathrm{kV} / \mathrm{m}$. The slope of the zero crossing must be negutive to guaranitee that the phase of the beam is $0^{\circ}$ and not $180^{\circ}$ out of phase. The phase setpoiat determined by this method is then uned with gndient and phase loop closed to mockentie bean con crest.

The phase of the beam-thduced voltage is offuet by the detuning angle which is measured with an accurncy of $\pm 5^{\circ}$. The precision of the detuning angle measurement limits therefore the sceuncy of this otberwive very preclse mensurement.

\section{CALCULATED PHASE SETTINGS}

Tre phase of the accelenting field relutive to the beam $\mathrm{cm}$ be calculated from mown electrical length of cables, other coetrol module compooents such as the down conventer, and the time of flight of the electron beam converted to phase. All ignals are referenced to a coenmon master oscillator. Cable length of more than a kiloeneter over the whole accelerator wive and effects from vemperature chinges do not allow for tigh cocuracy. Nevertheless it is possible to calculate the phase difference between the cavities in coec cryonodule within $\pm 5^{\circ}$. ne probe cable leagth and phase offiets in the control module can be mearured better than $\pm 2^{\circ}$ as achieved in recent lests. Also error to time of night due to mechanical position of the cavily, which can change by up to $\pm 0.5 \mathrm{~cm}$ as function of imer poelition, contribute io the ovenall errox.

\section{vIII. CONCLUSION}

Sevenal methods for the adjustment of the phase of the cocekenting field have been tested in the CBB NF acoelenstor during the commisticoing phase of the sorth linac. Phesing with the spectrometer is time consuming expecially for the mitial phasiag for the aceelernator. Ooce the cavity phase is adjusted within $\pm 40^{\circ}$ en autoenated algorithm will correct for difits. Only one cavity can be doee at a time. Ober methods allow for simulumeous phasing of several cavities and are 由erefore, since faster, more desinable during sceelenator operatioa. The cavity phasing using beam modulation can postibly be used while beam is delliverod to the experiments. A comparison of the differeat metbods is given in Tuble 3. The most nensitive method is the phasing waing beam-induced endient in CW mode, but it relies on procise bnowledge of the decuning angle.

Thble 3: Comprison of the Phasing Methods

\begin{tabular}{|c|c|c|c|}
\hline Method & $\begin{array}{l}\text { Acouncy } \\
\text { mer. (best) }\end{array}$ & $\begin{array}{l}\text { Dedicied } \\
\text { beann time }\end{array}$ & 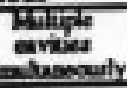 \\
\hline Spectrometier & $23^{*}\left( \pm 2^{*}\right)$ & $\overline{N_{0}}$ & No \\
\hline Beam ind. trane. & $\pm 2^{*}\left( \pm 1^{*}\right)$ & Yes & Yes \\
\hline Beam modvintion & $\pm 5^{\circ}\left( \pm 2^{*}\right)$ & No & Yes \\
\hline Beam ind trad. & $\pm 5^{*}( \pm 39)$ & Yes & Yes \\
\hline Caleulation & $\pm 5^{\circ}\left( \pm 2^{\circ}\right)$ & $N_{0}$ & $Y_{e}$ \\
\hline
\end{tabular}

\section{Actnowledgments}

The suthors wish wo express their thanks w $\mathrm{M}$. Angustine, C. Hovater, the matintenance group, and Opernitions Crew for their coormous help th machine opernilioe and data sequisitice.

\section{REFERENCES}

1. G. Knm, J. Bleognasa, L. Merningen S. Simrock, these procesdings.

2. G. A. Krafr, S. N. Stmrock, and X. L. Maboney. Proceedings of the 1990 Linear Accelerntor Conference, p. 300.

3. K. Cnwiond, M. O'Sullivin, J. Perry, S. Simrock, these proceedings. 